\title{
A Conceptual Framework for Modeling Awareness Mechanisms in Collaborative Systems
}

\author{
Fernando Gallego, Ana Isabel Molina, Jesús Gallardo, and Crescencio Bravo \\ Computer Science Department. University of Castilla - La Mancha \\ Paseo de la Universidad, 4, Ciudad Real, Spain \\ \{Fernando.Gallego, AnaIsabel.Molina, Jesus.Gallardo, \\ Crescencio.Bravo\} @uclm.es
}

\begin{abstract}
Awareness is defined as the perception of the activities being carried out by members of a team in a given context. The use of awareness support techniques reduces the effort needed to realize communicative and collaborative tasks. Therefore, this leads to an increase in group work productivity. In this article we propose a conceptual framework which improves upon the process of building interactive collaborative systems as proposed by CIAM (a methodological framework for designing interactive applications for group work) by taking the dimension of awareness into consideration.
\end{abstract}

Keywords: Awareness, Meta-modeling, Groupware.

\section{Introduction}

The use of technologies for awareness [1] support in collaborative systems allows users to stay informed about the activities that are being carried out by other users, as well as in which parts of the shared working area they are working and how those activities are being carried out. Therefore, the incorporation of elements for awareness support makes it possible to reduce the meta-communicative efforts which are needed to carry out collaborative activities oriented towards promoting real collaboration between group work members. Other proposals [2, 3, 4] in the field of awareness modeling in collaborative systems usually focus on the domain of awareness design in interactive systems, but do not take into account any specific technological implementation.

Molina et al. [5] have reviewed the different existing proposals in the field of model-driven specification of collaborative interactive systems. We can conclude that none of them provides a proper specification for users' needs regarding awareness much less any systematic or computational support for modeling this characteristic. One of these proposals is the CIAM methodological framework [6]. Its related notation, called CIAN [7], provides support for modeling collaboration, interaction and shared context. Shared context is defined as a set of objects where both the objects and the actions performed on them are visible to a set of users [8]. In group work tasks with a shared context (collaborative tasks), awareness mechanisms are very important because they provide a noticeable improvement to group work productivity. Therefore, the main objective of our work is: to incorporate the 
modeling of these awareness aspects into the modeling of collaborative tasks in the context of CIAM.

In the next section we briefly show our framework for modeling awareness mechanisms, and in Section 3 we present the conclusions and future lines of work derived from this work.

\section{A Conceptual Framework for Designing Awareness Support in Collaborative Tasks}

To specify which group awareness concepts should be included in the CIAN notation we started by defining a meta-model (Figure 1) which includes the concepts and groups them into different views:

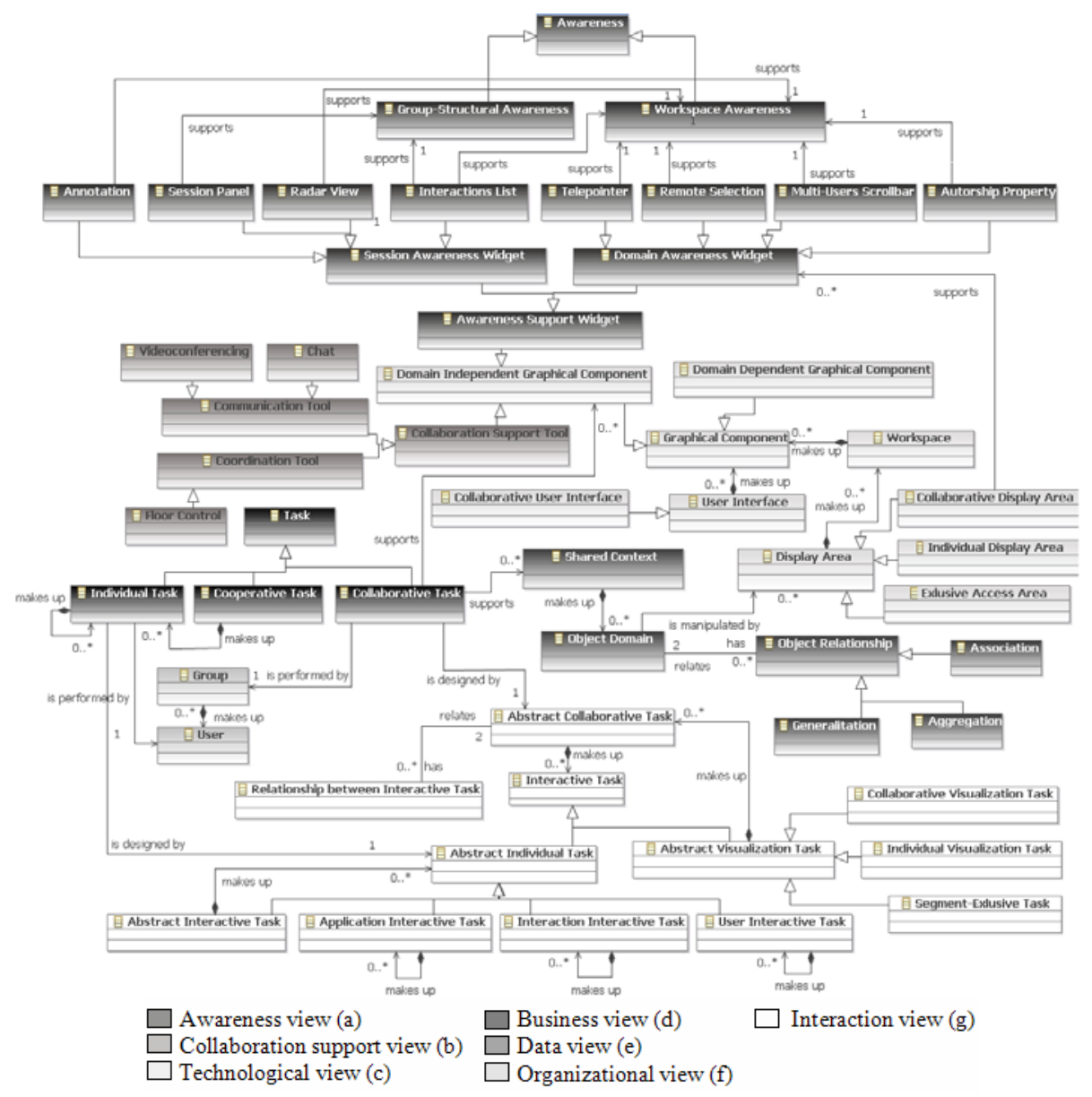

Fig. 1. The Proposed meta-model 
Table 1. Definition of Widgets for Awareness Support

\begin{tabular}{|l|l|l|}
\hline Widget & Type & Description \\
\hline Radar View & $\begin{array}{l}\text { Session Awareness } \\
\text { Widget }\end{array}$ & $\begin{array}{l}\text { Widget that shows the area in which users are } \\
\text { working and the activities they are undertaking. }\end{array}$ \\
\hline Telepointer & $\begin{array}{l}\text { Domain Awareness } \\
\text { Widget }\end{array}$ & $\begin{array}{l}\text { Graphical cursor that indicates the position of the } \\
\text { mouse pointer of a user who is interacting with } \\
\text { the shared context. }\end{array}$ \\
\hline $\begin{array}{l}\text { Authorship } \\
\text { Property }\end{array}$ & $\begin{array}{l}\text { Domain Awareness } \\
\text { Widget }\end{array}$ & $\begin{array}{l}\text { Widget that shows, for each object in the shared } \\
\text { context, the user who created it. }\end{array}$ \\
\hline Interactions List & $\begin{array}{l}\text { Session Awareness } \\
\text { Widget }\end{array}$ & $\begin{array}{l}\text { Widget that shows, textually, the interactions } \\
\text { taking place during a work session. }\end{array}$ \\
\hline $\begin{array}{l}\text { Multi-User } \\
\text { Scroll Bar }\end{array}$ & $\begin{array}{l}\text { Domain Awareness } \\
\text { Widget }\end{array}$ & $\begin{array}{l}\text { Widget that shows the location of each user in the } \\
\text { work area according to the position of the scroll } \\
\text { bar. }\end{array}$ \\
\hline Annotation & $\begin{array}{l}\text { Session Awareness } \\
\text { Widget }\end{array}$ & $\begin{array}{l}\text { Brief text note which a user can publish in order } \\
\text { to share messages asynchronously. }\end{array}$ \\
\hline Session Panel & $\begin{array}{l}\text { Session Awareness } \\
\text { Widget }\end{array}$ & $\begin{array}{l}\text { Widget that shows the actors who are involved in } \\
\text { a session, with additional information about them. }\end{array}$ \\
\hline $\begin{array}{l}\text { Remote } \\
\text { Selection }\end{array}$ & $\begin{array}{l}\text { Domain Awareness } \\
\text { Widget }\end{array}$ & $\begin{array}{l}\text { Widget that shows objects in the shared context } \\
\text { that have been selected by other users. }\end{array}$ \\
\hline
\end{tabular}

The Organizational view (Figure 1.f) includes concepts related to the group work members; the Data view (Figure 1.e) includes concepts related to the domain and to the data manipulated within the shared context; the Technological view (Figure 1.c) considers the implementation of awareness mechanisms and interactive activity issues, such as the components and workspaces which may go into making up the application's GUI; the Collaboration support view (Figure 1.b) includes the concepts related to communication and coordination support; the Interaction view (Figure 1.g) includes the concepts related to the modeling of interactive issues in the application; the Business view (Figure 1.d) includes the entities involved in the design of tasks, regardless of the technology used; and, finally, the Awareness view (Figure 1.a) includes those concepts which are directly related to awareness support.

Awareness support at the implementation level results in the inclusion of graphical elements (widgets) in the user interface. Table 1 shows the widgets for awareness support considered in our proposal, along with a brief description of each of them. We have classified the awareness support widgets into two different types: Session Awareness Widgets and Domain Awareness Widgets. These widgets and the classification, which considers what kind of information is handled in each case, are part of the Awareness view in the meta-model (Figure 1.a).

\section{Conclusions and Future Work}

In this paper we have introduced a meta-model which allows for the identification of those concepts related to awareness which should be considered in any proposal for the modeling of interactive groupware systems, such as the proposal we ourselves have worked with: that of the CIAM approach. Once these concepts had been 
identified, along with the relationships between them, the next step was to define a graphical notation for modeling them. In our case, we opted to take the CIAN graphical notation as our starting point.

Our work in the future will be to define the visual appearance of the notation and to implement a software tool with support for modeling related to our meta-model. This implementation will be developed using meta-model-based graphical editor technologies. Specifically, these will be technologies such as EMF $^{1}$ (Eclipse Modelling Framework) and $\mathrm{GMF}^{2}$ (Graphical Modelling Framework). By using these technologies, it will be possible to test the semantics of the generated models, and to validate the proposed meta-model. This tool will support the semi-automatic generation of collaborative interfaces from CIAN models and interaction models, both enriched with awareness support elements.

Acknowledgements. This work has been partially supported by the iColab project, funded by the Junta de Comunidades de Castilla-La Mancha (Spain), and by the ProgCoLab project, funded by the Universidad de Castilla-La Mancha (Spain).

\section{References}

1. Dourish, P., Bellotti, V.: Awareness and coordination in shared workspaces. In: Proceedings of the 1992 ACM Conference on Computer-Supported Cooperative Work, Canada (1992)

2. Gutwin, C., Greenberg, S.: A Descriptive Framework of Workspace Awareness for RealTime Groupware. Computer Supported Cooperative Work 11(3), 411-446 (2002)

3. Gallardo, J., Molina, A.I., Bravo, C., Redondo, M.A., Collazos, C.: An ontological conceptualization approach for awareness in domain-independent collaborative modeling systems: Application to a model-driven development method. Expert Systems with Applications 38(2), 1099-1118 (2011)

4. Kokar, M.M., Matheus, C.J., Baclawski, K.: Ontology-based situation awareness. Information Fusion 10(1), 83-98 (2009)

5. Molina, A.I., Redondo, M.A., Ortega, M.: A Review of Notations for Conceptual Modeling of Groupware Systems. In: New Trends on Human-Computer Interaction, pp. 1-12. Springer, London (2009)

6. Molina, A.I., Redondo, M.A., Ortega, M.: A methodological approach for user interface development of collaborative applications: A case study. Science of Computer Programming 74(9), 754-776 (2009)

7. Molina, A.I., Redondo, M.A., Ortega, M.: A Conceptual and Methodological Framework for Modeling Interactive Groupware Applications. In: Dimitriadis, Y.A., Zigurs, I., GómezSánchez, E. (eds.) CRIWG 2006. LNCS, vol. 4154, pp. 413-420. Springer, Heidelberg (2006)

8. Ellis, C.A., Gibbs, S.J., Rein, G.: Groupware: some issues and experiences. Communication of ACM 34(1) (1991) 